\title{
O DIZER DA ÉTICA E O DITO DA ONTOLOGIA: UMA ABORDAGEM
}

\author{
LEVINASIANA
}

\author{
The saying of Ethics and the said of Ontology: an levinasian \\ approach
}

Helder Machado Passos

UFMA

\begin{abstract}
Resumo: Pretende-se nesse artigo articular as noções de ética e política às noções do Dizer e do Dito, em uma perspectiva muito sutil apresentada por Emmanuel Levinas, para demonstrar como o sentido do humano se inicia na ética e necessariamente se dirige à política, uma vez que, para esse autor, a filosofia tem que ir ao fato social. Essa articulação se torna possível pela noção de justiça presente em dois momentos do humano: o momento inicial do frente a frente do Eu e do Outro ou ética e o momento em que a pluralidade se torna real pela presença do Terceiro, ou política. A preocupação levinasiana é, não só a de afirmar a primazia da ética em relação à política, no que diz respeito à ordem do acontecimento, mas também de demonstrar que a presença do Dizer original do frente a frente que se inscreve como exigência de justificativas para um Eu absoluto, deve permanecer na relação política, quando em sua impostação institucional a partir da Lei e do Estado pretenderem absolutizar-se em relação as demandantes da própria justiça. Assim, o Dito da Lei está sob os auspícios de um novo Dizer que pode destituir a razoabilidade daquele, exatamente pela presença de Terceiros, diferentes e não incluídos na ordem jurídica. A ordem politico-jurídica que em sua demora tem feições ontológicas, quando não se abre para o Dizer perene, pode tornar-se ordem violenta, tal qual a ordem que prepondera no fenômeno da guerra. O sentido do humano, segundo Levinas está na démarche da relação dual do frente a frente à multiplicidade das relações políticas alicerçadas na noção de justiça como exigência de justificação para a ação.
\end{abstract}

Palavras-chave: Ética; Ontologia; Justiça; Lévinas.

Abstract: In this article is intended to articulate the notions of ethics and politics to the notions of the Saying and the Said, in a very subtle perspective presented by Emmanuel Levinas, to demonstrate how the human's meaning begins in the ethics e necessarily addresses to the politics, since, to this author, the philosophy must point to the social fact. This articulation is possible through the notion of justice present in two moments of human life: the initial moment of the front to front of the Me and the Other, or ethics, and the moment when the plurality becomes real because of the presence of the Third, or politics. The levinasian concern is not only to affirm the ethics primacy regarding politics, with respect to 
the order of the happening, but also to demonstrate that the presence of the original Saying of the front to front, which appear as a demanding of justifications to an absolute Me, must subsist in the politics relation, when its institutional impostor from the Law and the State tend to absolutize itselves in relation to the justice demands. Therefore, the Said of the Law is under the auspices from a new Saying that can deprives the reasonability of that, exactly because of the presence of Thirds, different and not included in the legal order. The political-legal order, that in its delay has ontological features when it does not open itself to the perennial Saying, can become a violent order, as the order that preponderates in the war phenomenon. The human meaning, to Levinas, is present in the démarche of the dual relation of the front to front to de multiplicity of the political relations grounded on the notion of justice as demanding of justifications for the actions.

Keywords: Ethics, Ontology, Justice, Lévinas.

O pensamento levinasiano se situa na contemporaneidade como um dos que mais se preocupam com questões morais, ou seja, um pensamento que se voltou mais especificamente para questões da moralidade de seu tempo. A questão premente de Levinas é pensar um sentido para o humano que não seja polarizado necessariamente pela guerra, ${ }^{1}$ fenômeno que alcançou importância capital na primeira metade do século XX. Tempo este que coincide com as experiências mais significativas de Levinas, tanto relativas à sua infância ainda em seu país de origem, a Lituânia, quanto em sua adolescência e idade adulta, na Ucrânia e na França, respectivamente, este último país que escolhera para viver.

O que está em jogo é a atmosfera que se sobrepõe às mentes e ações dos indivíduos numa Europa que, apesar de seus avanços culturais e científicos submete-se a um sentido para as relações sociais baseadas ou fundamentadas em um espírito beligerante, ou seja, Levinas aponta um descompasso entre a Europa das ciências e das artes e a Europa em seu quadrante político. ${ }^{2}$ A política exercida na Europa é a

\footnotetext{
${ }^{1} \mathrm{O}$ século $\mathrm{XX}$ foi palco de três grandes guerras que mobilizaram as vidas de milhões de pessoas de vários continentes. Levinas as viveu em diferentes fases de sua vida, mas talvez a mais significativa tenha sido a segunda guerra mundial, quando fora feito prisioneiro por longos seis anos em um campo de prisioneiros em Hanover, na Alemanha.

2 É pensar nessa atmosfera cultural que, especificamente em relação à Alemanha, temos personalidades e suas obras que expressam esse descompasso. Para citar apenas algumas dessas personalidades: Einstein, Mozart e Hitler. O próprio Levinas em entrevista a François Poirié comenta: "Mas, como bem sabe, é muito difícil comunicar isso, essa espécie de desespero ininterrupto que foi o período hitleriano
} 
política da guerra, que reivindica uma correção da ação prática a partir de um paradigma único que tem como maior expressão a eliminação da diferença que redunda em conquistas, em anexação de territórios e eliminação de identidades diversas. Levinas se recusa a aceitar que esta é a condição da evolução humana. Catherine Chalier, em sua obra A utopia do humano (2003) pontua essa preocupação levinasiana.

\begin{abstract}
Mais tarde, afirmará que um século dominado por tantas recordações terríveis - Auschwitz, Hiroxima, o Gulag, o genocídio do Camboja - uma actualidade angustiante, não pode absolutamente continuar a acreditar que os milhões de infortúnios singulares que estas palavras terríveis evocam sejam a condição de um progresso (CHALIER, 1993, p. 61).
\end{abstract}

O sentido do humano que, segundo Levinas, está posto no ambiente referido é descrito como um não sentido, como algo que paira sobre os sujeitos, mas que os mesmos não conseguem identificar suas raízes e sua razão de ser. Em uma de suas primeiras obras, Da Evasão (1947), Levinas identifica esse estado de coisas e o nomeia com a expressão francesa, /l y $a$, que normalmente se traduz para o português pela expressão Há que segundo o autor, nos dá a ideia de impessoalidade, de obscurecimento, de afastamento da realidade ou de uma vida sem sentido. O Há, dá o tom de uma indefinição dos responsáveis pelo estado de coisas, e, neste sentido, compreende-se a realidade da guerra como um fluxo necessário, como se os indivíduos devessem aceitar essa existência dada. O que impera é o neutro, a escuridão, que reverbera a solidão e a cegueira dos sujeitos humanos quanto ao que fazer de suas vidas, a não ser imiscuir-se no Há ou deixar-se levar pela onda, neste caso a onda da guerra.

Para Levinas, dentre as várias razões de ser dessa época, a mais significativa é a filiação do espírito europeu à filosofia, ou seja, essa atmosfera é fruto de uma

da Europa, erguendo-se do fundo dessa Alemanha tão fundamental, dessa Alemanha de Leibniz e de Kant, de Goethe e de Hegel..." (LEVINAS, Apud POIRIÉ, 2007, p.73). 
orientação filosófica que não pensou o fora do $\operatorname{Ser}^{3}$ e, portanto não pensou a relação entre o Ser e o fora de si. Assim a tradição filosófica arranjou-se em um modelo ensimesmado em que tudo se resume ao movimento para dentro do Ser.

Certamente, essa questão da ausência de uma exterioridade em referência à existência do Ser como única, impacta significativamente qualquer pensamento que se ocupe com a dimensão da moralidade, uma vez que a mesma pressupõe diferença, separação entre os termos ou entes que se relacionam. A propósito da gravidade da ausência de separação entre os termos da relação prática, nos diz Levinas:

\footnotetext{
Sem separação, não teria havido verdade, apenas teria havido ser. Verdade - contato menor que a tangência - no risco da ignorância, da ilusão e do erro não recupera a "distância", não chega à união do cognoscente e do conhecido, não chega à totalidade ( LEVINAS, 2008, p. 48).
}

Para os leitores de Levinas, mesmo os seus críticos, seu interesse maior, que está presente em todas as fases de seu pensamento, é a possibilidade de pensar um modo de vida humana que seja orientado por um sentido para o humano que se refira a entes que se relacionam para além de um modelo paradigmático que prioriza a interioridade do Ser, ou seja, um sentido que além de relacionar-se com a proximidade, também seja capaz de conceber o distante, o distinto como elemento que compõe a socialidade.

Vejamos que, quando se diz proximidade e distancia, no pensamento levinasiano, isso significa separação, condição fundamental para se pensar o próprio humano em suas relações práticas que não seja sinônimo de dominação em qualquer nível. A noção de separação não denota iminência de conflitos ou disputas que redundem em violência, mas é pela separação que se pode pensar em relações práticas em que os termos dessa relação não se anulem, um pelo outro. A separação é o que marca a possibilidade de relações práticas em que a identidade e alteridade não

\footnotetext{
${ }^{3} \mathrm{O}$ termo Ser quando se referir à unidade ontológica terá sua primeira letra grafada em maiúscula. Da mesma forma os termos Há, Eu, Outro, Dizer e Dito, quando se referirem a termos próprios do pensamento levinasiano.
} 
perdem seus postos, mantendo assim a própria relação. Neste caso, exigi-se uma separação radical, sem meios termos ou sem concessões.

A separação só é radical se cada ser tiver o seu tempo, isto é, a sua interioridade, se cada tempo não for absorvido no tempo universal. Graças à dimensão da interioridade, o ser recusa-se ao conceito e resiste à totalidade (LEVINAS, 2008, p. 45).

Estamos já no cerne da filosofia, ou seja, é na filosofia, no ambiente dela que Levinas busca discutir essas questões e a principal referência à filosofia se dá à sua impostação ontológica, pois não é difícil identificarmos o sentido de interioridade e totalização que está presente em toda a história da filosofia como ontologia. Assim a compreensão de um movimento para a interioridade que define a realidade como uma totalidade determina a impossibilidade do diferente da totalidade, portanto, uma realidade diferente ou exterior ao Ser. Desta forma a crítica à ontologia parece ser necessária, uma vez que segundo nosso autor, o estado de coisas vivido em seu tempo está diretamente ligado à forma, ao modo como a filosofia é apresentada, ou seja, como ontologia.

A face do Ser que se mostra na guerra fixa-se no conceito de totalidade que domina a filosofia ocidental. Os indivíduos reconduzem-se a portadores de formas que os comandam sem eles saberem. Os indivíduos vão buscar a essa totalidade sem sentido( invisível fora dela). A unicidade de cada presente sacrifica-se incessantemente a um futuro chamado a desvendar o seu sentido objetivo. Porque só o sentido último é que conta, só o último ato transforma os seres neles próprios. Eles serão o que aparecerem nas formas, já plásticas da epopeia (LEVINAS, 2008, p. 08).

É a partir desta constatação que Levinas se impõe a tarefa de pensar outro sentido para o humano que não seja o já posto, o referido a um paradigma fechado do Ser da ontologia.

A crítica levinasiana em relação à ontologia vai para aquém de sua pretensão de dizer unicamente sobre a realidade, mas também ao fato de que ela pretende ser a própria origem da filosofia, da origem desse modo dizer sobre a realidade. 
Surge então a questão com a qual Levinas se ocupará durante boa parte de sua obra, principalmente em Totalidade e infinito, que é a defesa de que, ao revés da ontologia, a ética é a filosofia primeira ${ }^{4}$.

Para Levinas, o início de tudo, da filosofia, não é uma ponderação, um arrazoado, mas um questionamento, uma impugnação. Deste modo todo o edifício do pensamento humano está alicerçado neste primeiro balbucio do humano que se dá como interrogação oriunda de um termo que não está submetido a uma ordem dada.

\begin{abstract}
Chama-se ética a essa impugnação da minha espontaneidade pela presença de Outrem. A estranheza de Outrem - realiza-se precisamente como um por em questão da minha espontaneidade, como ética. A metafísica, a transcendência, o acolhimento do Outro pelo Mesmo, de Outrem por Mim produz-se concretamente como a impugnação do mesmo pelo Outro, isto é, como a ética que cumpre a essência crítica do saber. È tal como a crítica precede o dogmatismo, a metafísica precede a ontologia (LEVINAS, 2008, p. 30).
\end{abstract}

Para aqueles que têm contato com a obra deste autor, saberão que toda a sua filosofia tem como ponto fulcral a relação Eu-Outro em um instante denominado de frente a frente.

É nesse instante em que o tempo é mínimo, quase que irrisório em termos de métrica, que o Eu, como sujeito e identidade perde toda a sua condição de doador exclusivo de sentido da realidade. No frente a frente, o outro termo, o Outro, é um questionador, um exigente de justificativas ${ }^{5}$ sobre a ação do sujeito, até então livre, ensimesmado em seus afazeres, que não quer dizer obrigações, mas apenas movimentos interessados.

\footnotetext{
${ }^{4}$ Cumpre observar que Levinas compreende a ética como uma relação metafísica, na medida em que a relação entre o Eu e o Outro se dá metafisicamente, isto porque o Outro, pelo seu caráter de infinição é transcendente em relação ao Eu. Deste modo, pode-se dizer que o termo ética é sinônimo de metafísica. Ambos constituem-se como filosofia primeira.

${ }^{5}$ Justificativa, como exigência do Outro em relação ao Eu, exprime o primeiro sentido de justiça, no pensamento levinasiano. Exigir justificativas é exigir justiça. Responder às justificativas é ser justo. É importante ressaltar que esse primeiro sentido de justiça recai única e exclusivamente sobre o Eu, portanto não se pode falar em relações recíprocas de justiça. A reciprocidade, só poderá ser pensada, em um nível de relação para além do frente a frente. Um pouco a frente trataremos dessa questão.
} 
Esse questionamento se dá pela presença do Outro como Rosto, ou seja, o Rosto se constitui como a primeira pergunta, a primeira fala. Assim confirma Levinas:

É precisamente isso que nós descrevemos pela fórmula: o rosto fala. A manifestação do rosto é o primeiro discurso. Falar é, antes de tudo, este modo de chegar por detrás de sua aparência, por detrás de sua forma, uma abertura da abertura (LEVINAS, 1993, p. 51).

O Outro tem a ossatura de um enigma, que se apresenta como vestígio e pela sua condição de infinição ${ }^{6}$, não se deixa captar, cumular, conhecer. É essa infinição do Outro que faz com que Ele não seja objeto de conhecimento ou objeto de dominação por parte do sujeito.

O que gostaríamos de pontuar sobre esta relação é que a presença do Outro frente ao Eu se faz como linguagem sem signos definidos, sem conceitos e sem representações, portanto sem arranjos racionais e, como consequência, não pode ser concebida como uma relação ontológica, uma vez que o movimento de totalização fica desprovido de possibilidades porque não há um logos prévio.

O elemento que faz o Eu sentir a presença/ausência do Outro está, como dissemos, no campo da sensibilidade e não no campo da razão, mas é essa sensibilidade que faz com que o Eu não se sinta só no mundo. Esse é o momento em que Ele se reconhece como não estando só no mundo, embora não saiba sobre quem Ihe faz companhia.

Presença que incomoda, que questiona sobre meus poderes, que desestabiliza, que exige de mim uma justificativa para meus atos.

Para Levinas, o frente a frente é linguagem. Como bem sublinha Milovic: "A linguagem só existe, ou apenas precisamos dela, caso exista o Outro. A essência da linguagem está nessa hospitalidade com relação a Outrem" (MILOVIC, 2004, p. 119).

\footnotetext{
${ }^{6} \mathrm{O}$ termo infinição é utilizado por Levinas para identificar a condição do Outro como infinito. A infinição é o que permite ao Outro não ser submetido pelo Eu, em seu afã de conhecimento que resulta em seu ensimesmamento .
} 
Linguagem sem signos e significados prévios e que só a partir deste momento poderá ser significada. Um Dizer que não parte de um Dito.

Doravante, a partir dessa relação inicial sem preâmbulos que Levinas identifica como o instante inicial da filosofia, poderemos falar em signos com significados, em conceitos e representações, em racionalidade, portanto, em algo que tenha sentido e seja compreensível para uma comunidade de entendedores. Passamos a considerar um espaço racional. Um espaço em que, de algum modo, os sujeitos se referem de forma simetrizada. ${ }^{7}$ Isto porque os conceitos e representações foram fixados. Há uma referência prévia.

Aqui começa a ser posta a questão que pretendemos apresentar, qual seja: a ética como filosofia primeira é primeira porque é o espaço da primeira palavra que é o Dizer do Outro e que provoca uma resposta do Eu. Todo esse diálogo primário quando pronunciado já se fixa como um Dito, que se faz demorar e que só não demora mais porque pode ser desdito por um novo Dizer. Não interessa quanto tempo, se fração de segundos ou décadas o Dito permanece como tal, pois ele se instaura ou instaura na ou a ordem ontológica. Assim o Dizer está para a ética como o Dito está para a ontologia.

Já em sua obra, De outro modo que ser, uma passagem é esclarecedora:

\begin{abstract}
Por isto é que o homem é ser de verdade, sem pertencer a nenhum outro gênero de ser. Mas o poder de dizer no homem, qualquer que seja sua função, rigorosamente correlativa do Dito, está ao serviço do ser? Se o homem não fosse mais que Dizer correlativo ao logos, a subjetividade poderia compreender-se indiferentemente como um valor de função ou como um valor de argumento do ser. Mas a significação do Dizer vai mais além do Dito; não é a ontologia quem suscita o sujeito falante. Pelo contrário, é a significação do dizer que vai mais além da essência reunida no Dito a que poderá justificar a exposição do ser da ontologia ${ }^{8}$ (LEVINAS, 2003, p. 87).
\end{abstract}

\footnotetext{
7 Isto é importante resaltar, pois a relação ética é assimétrica no pensamento levinasiano. Toda a responsabilidade recai no sujeito, no EU. Já no âmbito da política é necessário simetrizar as relações, uma vez que a multiplicidade de sujeitos requer a responsabilização de todos.

${ }^{8}$ Tradução nossa
} 
Essa compreensão de Levinas parece ser mais clara quando avançamos para além da relação ética, pois com o surgimento do Terceiro ${ }^{9}$, elemento estranho à relação Eu-Outro, fica difícil não admitir uma sistemática, uma organização a que os indivíduos de uma comunidade devem se referir.

O Terceiro, com sua presença frente ao Eu e o Outro, impõe a exigência de reciprocidade ou simetria nas relações práticas. Daí surge a necessidade das instituições, da Lei e do Estado. Neste ponto, a Justiça como mediação entre os múltiplos surge como necessária e sem a qual a socialidade seria impossível.

\begin{abstract}
É a hora da justiça. O amor do próximo e seu direito original de único e incomparável pelos quais tenho de responder vêm eles mesmos fazer apelo à Razão capaz de comparar os incomparáveis, a uma sabedoria do amor. Uma medida se sobrepõe à "extravagante "generosidade do "para o outro", a seu infinito. Aqui, o direito de único, o direito original do homem postula o julgamento e, consequentemente, a objetividade, a objetivação, a tematização, a síntese. Há a necessidade de instituições que arbitrem e uma autoridade política que a sustente. A justiça exige e funda o Estado (LEVINAS, 1997, p. 248).
\end{abstract}

Neste caso, a justiça se origina de um Dizer que é primário e se faz na relação ética como exigência de justificativa de um para um torna possível a Lei como Dito que é originado de um Dizer e que passa a ser referência para todos os indivíduos que estão em relação. A justiça, neste momento, não mais é possível ser pensada como de um para um somente, mas de um para todos, de todos para um e de todos os modos que comporte a ideia de multiplicidade de indivíduos que exigem justificativas e ao mesmo tempo tenham que responder às exigências surgidas.

A relação inaugurada pelo Terceiro já não tem a dimensão dual, mas agora ela é plural para além de dois, de uma pluralidade que não tem uma finitude de termos, mas que comporta o Terceiro atual e todos os Terceiros atuais e futuros, próximos e

\footnotetext{
${ }^{9}$ A noção do Terceiro aparece com maior evidencia em sua obra De Outro Modo Que Ser. Ela, para muitos de seus leitores é a noção que permite a Levinas falar em socialidade e política. O Terceiro esgarça e rompe a quadratura da relação ética, exigindo atenção e cuidado para com ele e os demais chegados e por chegarem.
} 
distantes. Portanto, o Terceiro é o elemento que permite a difícil passagem da relação ética, de um para um, para a relação política, de um para muitos, de muitos para um e de muitos para muitos. Neste sentido observa Bensussan:

\begin{abstract}
O duo ético é sem máxima universalizável. Para dar razão, tanto quanto se pode, dessa dificuldade realmente considerável, Levinas convoca o terceiro, os terceiros seria necessário dizer, isto é, o tarde demais da relação ética, esta instancia pela qual a pluralidade dos outros do outro, a partilha, a reciprocidade, objetam e apelam (BENSUSSAM, 2009, p. 74).
\end{abstract}

Deste modo, para que a filosofia primeira, a ética possa perenizar-se no mundo dos sujeitos com a exigência de justificativas da ação do sujeito e de todos que se encontram nessa condição, como questionados e respondentes, o Dito, quase que traindo o Dizer, torna-se fundamental para que a filosofia possa ir ao fato social como preconiza Levinas: “Aliás, não acredito que a filosofia possa ser pura sem ir ao 'problema social'"' (LEVINAS, 2010, p. 42). Gostaríamos de tentar explicar essa relação entre ética e ontologia (política), Dizer e Dito, sensibilidade e razão a partir de um dos subcapítulos de nossa tese de doutorado. ${ }^{10}$

Dizemos lá que em Levinas “a política extrapola a ética, e a ética interrompe a política." A política extrapola a ética porque pode levar sua exigência de justificativas a um espaço maior e mais complexo que a relação ética e a ética interrompe a política porque tem a prerrogativa do Dizer que desdiz ou diz de outro modo o que está inscrito como princípio relacional, seja no modo como a justiça é administrada ou como seus preceitos são manipulados e interpretados, seja na própria formulação de preceitos legais, como a Constituição ou outras leis que dela derivem.

Em termos de realidade, a ética e sua palavra inicial, não estão supostos na vida dos indivíduos, na maioria dos tempos e dos grupamentos humanos. Pode-se constatar que a ética é um Dizer que não está sempre ou quase nunca como pressuposto para a consecução das relações políticas, e segundo Levinas, é por esta

10 Tese defendida no programa de pós-graduação em filosofia da Universidade de São Paulo em dezembro de 2012, intitulada: Relação ente Ética e Política no pensamento de Emmanuel Levinas. 
razão que os arranjos políticos quase sempre resultam em violência, porque oriundos de um sentido que imprime a ação do sujeito ou de sujeitos de si para si. ${ }^{11}$

Em geral, e isso é a constatação levinasiana sobre seu tempo, a política reflete um Dito que não sabe sua origem e nem se põe a possibilidade de ser destituído. Significa que, de algum modo, a política assume um sentido para o humano sem considerar os Terceiros chegados e suas demandas próprias.

O questionamento, a solicitação de atenção para aqueles que não eram considerados em si e em suas demandas, faz com que o Dito legal, a orientação e administração da política sejam questionadas. Não supor essa possibilidade é se colocar em uma condição de imutabilidade, de resistência à mudança na ordem social e política.

É na perspectiva de desfazer o equívoco de uma política baseada na totalidade do Ser como única possibilidade de sentido que Levinas propõe a ética como filosofia primeira a partir do frente a frente com o Outro, resultando desse encontro a palavra inicial como Dizer que prescinde da marcação de sua demora, pois se dá em um tempo menor que se possa medir. Qualquer demora já é Dito, mas nada garante a sua permanência, a não ser a demora de um novo Dizer.

Se o Dizer é a palavra primeira da ética e o Dito a palavra que se demora como política, por exemplo, resulta que, para Levinas, não se pode deixar a política a si mesma, sob pena de totalizar-se, de fechar-se, de estabelecer uma unidade e impedir a fala de um Terceiro não compreendido, portanto de ir até onde existam humanos que necessitem ser considerados. Decorre daí, dessa preocupação, a compreensão de que a racionalidade pressuposta no exercício da política e particularmente, na administração da Lei como exercício da justiça, deve supor a abertura para novas configurações da própria Lei como exigência do Terceiro que se pronuncia com um

\footnotetext{
${ }^{11}$ Cabe ressaltar a relação que Levinas apresenta entre a tradição filosófica ocidental e as chamadas filosofias da consciência, uma vez que as mesmas, por estabelecerem uma primazia do sujeito, na dinâmica do conhecimento, acabam por reforçar o movimento ontológico de cumulação do Outro pelo Eu.
} 
Dizer. O Dizer é a origem do discurso, de qualquer discurso que se pretenda razoável, trazendo em si a razoabilidade do próprio fluxo da realidade.

O tempo exige do discurso um contínuo desdizer para dizer outramente Há que se perceber a anterioridade absoluta daquilo que é dito com relação ao próprio dito. Significa que o discurso toca a realidade com palavras, mas não consegue conter seu conteúdo que escorrega no mesmo instante em que um dito se articula. A tônica pertence ao Dizer e ao dizendo diacrônico. Reinventa-se dessa forma o próprio sentido da razão humana. A razão que articula a linguagem compromete-se com a indissolubilidade entre os mundos em relação (FARIAS, in. SUSIN, 2003, p.191).

O enunciado do Dizer, para se fazer presente nas relações práticas mais largas que a relação ética, necessita do Dito, mesmo que este, em certo sentido, traia a condição do Dizer. "'O dito' atraiçoa 'o dizer' - como já vimos - mas a única possibilidade de anunciar 'o dizer' é pagando o preço de atraiçoa-lo num 'dito'” (COSTA, 2000, p. 156).

Assim, o Dizer se liga à ética e o Dito à política que tem, para seu bom funcionamento a necessidade de uma palavra que demora, mas que não pode eternizar-se necessariamente.

Podemos a partir dessa afirmação, deduzir que, se o Dizer é a primeira palavra que inaugura a possibilidade do diálogo, a partir da exigência de justificativas resultando em resposta e que esse primeiro contato se dá eticamente sem pressupostos racionais; do mesmo modo, podemos deduzir que o Dito que resulta desse primeiro contato se mantém como conceito, como representação, portanto dentro de um espectro racional.

O Dito só deve se demorar se mantiver a racionalidade necessária para a sua manutenção. Em certo sentido, essa manutenção é o que liga o Dito à ontologia, ou seja: a política, a justiça, a Lei e todos os arranjos racionais tem uma ligação com a ontologia enquanto demora no Ser.

O problema que Levinas encontra na ontologia como discurso sobre o Ser é sua fixação no próprio Ser, impossibilitando qualquer possibilidade da diferença 
reivindicar sua existência e consideração. Neste caso, para Levinas, a demora ontológica dos artefatos normativos inscritos em um Dito, são absolutamente compreensíveis. O que não é compreensível é o fechamento desses artefatos ao que chega por último, ao que não foi suposto, ao que não estava presente na hora do contrato. $^{12}$

Assim fica compreendido que Levinas não quer destituir a ontologia de sua função racionalizante inscrita no Dito, como demora no Ser, mas demonstrar que a mesma deriva da palavra primeira, do Dizer que caracteriza a ética.

Para não nos alongarmos e ao mesmo tempo estabelecermos uma conexão com a realidade da vivência humana, tomaremos como exemplo o ordenamento jurídico que é, por assim dizer, a referência de toda e qualquer organização política contemporânea, pelo menos em termos de ocidentalidade. Demarquemos ainda um pouco mais e nos atenhamos ao Estado de Direito brasileiro.

Para quem quiser ver esse fenômeno da relação ética e política na sociedade brasileira, basta observar a quantidade de leis que deixam de viger e das muitas outras que passam a exercer seu poder de orientação.

Um caso que vem à memória como paradigmático do que se está a argumentar aqui a partir das teses levinasianas é a Lei "Maria da Penha", Lei n 11.340, de 7 agosto de 2006. ${ }^{13}$ Uma demanda de um Terceiro, a senhora Maria da Penha, interrompeu o ordenamento jurídico, seja por conta de leis que não a amparavam, seja pela omissão em sua demanda por parte dos operadores do direito e produziu com seu Dizer, sua exigência de justificativa ou de justiça, um Dito que a partir de

\footnotetext{
12 A propósito da idáia de um contrato que funda a justiça e de uma justiça antes de qualquer contrato, que é o caso da tese levinasiana da justiça como exigência de justificativa, apontamos, a título de exemplo da primeira compreensão o pensamento de John Hawls. Segundo esse autor só se pode pensar em justiça, após a fixação pelos participantes de uma sociedade que, sob a forma de um contrato, decidem o que é justo.

${ }^{13}$ Cria mecanismos para coibir a violência doméstica e familiar contra a mulher, nos termos do $\S 8^{\circ}$ do art. 226 da Constituição Federal, da Convenção sobre a Eliminação de Todas as Formas de Discriminação contra as Mulheres e da Convenção Interamericana para Prevenir, Punir e Erradicar a Violência contra a Mulher; dispõe sobre a criação dos Juizados de Violência Doméstica e Familiar contra a Mulher; altera o Código de Processo Penal, o Código Penal e a Lei de Execução Penal; e dá outras providências.
} 
então passou a orientar todos os sujeitos dessa coletividade. Neste caso, a justiça como instituição política passa a ter outra orientação para casos de violência contra a mulher. Um novo Dito se estabeleceu a partir de um Dizer inesperado, não suposto.

O Dizer, portanto liga-se à ética como primeira palavra que provoca uma resposta. É o início de todo o sentido do humano. O Dito conserva em si, como demora, este sentido original e reverte-o para todos os sujeitos da coletividade, tornando-se a base de toda política.

É forçoso concluir que, baseado no pensamento Levinasiano, a ética se relaciona com a política como renovadora da mesma, impedindo-a de cristalizar-se, de eternizar-se em suas orientações. Isto é o modo mais claro de fazer violência contra os seres humanos, atuais e futuros, quando os mesmos não cabem no Dito hodierno.

Para evitar tal realidade, que é a realidade da perpetração de toda violência humana, tanto macro como micro, Levinas propõe a ética como Dizer profético, renovador da lei, dos costumes e de tudo aquilo que orienta a vida em comunidade.

\begin{abstract}
Mas a própria justiça não conseguiria fazer esquecer a origem do direito e a unicidade de outrem que recobrem doravante a particularidade e a generalidade do humano. Ela não poderia abandonar esta unidade à história política que se encontra engajada no determinismo dos poderes, das razões de estado, das tentações e das facilidades totalitárias. Ela aguarda as vozes que relembram aos julgamentos dos juízes e dos homens de Estado o rosto humano dissimulado sob as identidades de cidadãos. Estas seriam, talvez, as "vozes proféticas" (LEVINAS, 1997, p. 248).
\end{abstract}

Certamente, aqui encontramos um sopro das lições bergesonianas, relativas à sua compreensão da moral como composta de um elemento fechado e outro aberto que se inscrevem na tradição e em uma fala profética respectivamente. Neste sentido, podemos aproximar o elemento da tradição ao Dito e a fala profética ao Dizer.

Revendo a questão que fora proposta no inicio desse artigo, qual seja, a caracterização do Dizer relativo à ética e o Dito relativo à ontologia, e ainda considerando a tentativa levinasiana de estabelecerr um sentido para o humano que não esteja ele, o sentido, pautado em uma realidade fechada e obscura que permita a 
compreensão da guerra como natural e necessária, consideramos ser bastante alviçareira a propositura levinasiana de fazer derivar a Lei e a constituição do Estado de Direito, da palavra inicial do frente a frente.

Mais oportuno para um sentido do humano que não fique encalacrado em um Dito eterno, que pela sua eternidade pode violentar porque deixa de fora os novos chegados e suas demandas é compreender que um novo Dizer que seja capaz de destituir o Dito vigente, não o faz por violência, mas por respeito à própria realidade humana e suas vicissitudes.

Deste modo, os termos Dizer e Dito, ética e política (ontologia), serão percebidos como componentes necessários para a compreensão de uma realidade que longe de ser una e única, tem em sua composição o diverso, o diferente e para ele qualquer racionalidade, para ser compreendida como tal deve acolhê-lo. Assim, a razoabilidade da Lei, da Justiça, do Estado deve começar e se renovar pala palavra que clama por acolhimento, por justificativas de um Eu que não está só no mundo e que sua própria dignidade depende dessa disposição em considerar esse clamor. 


\section{Referências}

BENSUSSAN, Gérard. Ética e experiência: a política em Levinas. Tradução de Ozanan Vicente Carrara. Passos Fundo; IFIBE, 2009.

CARRARA, Ozanan Vicente. Levinas: do sujeito ético ao sujeito político. Aparecida: Ideias e Letras, 2010.

CHALIER, Caterine. Levinas: a utopia do humano. Tradução de Antonio Hall. Lisboa: Instituto Piaget, 2003.

COSTA, Márcio Luis. Levinas: uma introdução. Apresentação de Silvana Rabinovich e tradução de J. Thomaz Filho. Petrópolis: Vozes, 2000.

LEVINAS, Emmanuel. De outro modo que ser, o más Allá de La essência. Introdución e tradución de Antonio Pintor Ramos. Salamanca: Ediciones Sigueme, 2003.

.Ética e infinito. Tradução de João Gama. Lisboa: edições 70. 2010.

Totalidade e infinito: ensaio sobre a exterioridade. Tradução de José Pinto Ribeiro. . Lisboa: Edições 70, 2008.

Entre nós: ensaio sobre a alteridade. Coordenação e tradução de Pergentino Stefano pivatto. Petrópolis: Vozes, 1997.

LEVINAS, Emmanuel. De L'existence à L'existent. Paris: Libraire Philosophique J. Vrin, 1990.

Descobrindo a existência com Husserl e Heidegger. Tradução de Fernanda Oliveira. Lisboa: Instituto Piaget, 1997a.

Humanismo do outro homem. Coordenação e tradução de

Pergentino Stefano Pivatto e outros. Petrópolis: Vozes, 1993b.

MALFFETONE, Sebastiano e VECA, Salvatore. (Organizadores). A ideia de justiça: de

Platão a Hawls. Tradução Karina Janini; São Paulo. Martins Fontes, 2005. Dumará

MILOVIC, Miroslav. Comunidade da diferença. Rio de Janeiro: Relume, 2004. 
POIRIÉ, François. Emmanuel levinas: ensaio e entrevistas. Tradução de J. Guinsburg e outros. São Paulo: Perspectiva, 2007.

SUSIN, Luis Carlos e outros (Organizadores). Éticas em diálogo, Levinas e o pensamento contemporâneo: questões e interfaces. Porto Alegre: EDIPUCRES, 2003. 